\title{
Design Of Asthma Detection Devices Through Heart Rate and Oxygen Saturation
}

\author{
Selvi Indriani ${ }^{1}$, Endang Dian Setyoningsih ${ }^{1}$, Dyah Titisari ${ }^{1}$, Arif Joko Wuryanto ${ }^{2}$ \\ ${ }^{1}$ Department of Medical Electronics Engineering Technology of Politeknik Kesehatan Kementerian Kesehatan Surabaya \\ Jl. Pucang Jajar Timur No. 10, Surabaya (60282), Indonesia \\ ${ }^{2}$ Rumah Sakit Jiwa Sambang Lihum, Kalimatan Selatan \\ Indisindris08@gmail.com, diancholik@gmail.com,ti2_sari@yahoo.com
}

\begin{abstract}
Article Info
Article History:

Received May 15, 2020

Revised Nov 14, 2020

Accepted Nov 25, 2020

Abstract

Respiratory problems can cause asthma, acute asthma attacks are very difficult to predict because they often occur suddenly and asthma can also cause death in sufferers because the breath can suddenly stop. The purpose of this research is to design an asthma detection device through indicators of heart rate and oxygen saturation. The contribution of this study is to categorize the patient's condition by looking at the value of the heartbeat and oxygen saturation so that when asthma occurs the message of a location will be sent. To measure heart rate and oxygen saturation, a Nellcor finger sensor is placed on the patient's index finger. The finger sensor enters the signal conditioning circuit, then sent to the microcontroller to be processed to produce a heart rate value and the percentage of oxygen saturation. The testing of this tool is done by comparing the module with a standard measuring instrument that produces the highest value of oxygen saturation error which is $1.715 \%$ and the largest value of heart rate error is $3.548 \%$. The results showed that the device was appropriate to use, because in the Medical Devices Testing and Calibration Guidelines of the Ministry of Health of the Republic of Indonesia in 2001, the maximum limit in oxygen saturation error tolerance was $\mathbf{2 \%}$, and heart rate was $5 \%$. The results of this study can be implemented in patients who have been diagnosed with asthma so that it can facilitate the family in monitoring the patient's condition.
\end{abstract}

\section{Corresponding Author:}

Endang Dian Setyoningsih

Department of Medical Electronics Engineering Technology

Politeknik Kesehatan Kementerian Kesehatan Surabaya

J1. Pucang Jajar Timur No. 10, Surabaya (60282), Indonesia

E-mail:diancholik@gmail.com
This work is an open-access article and licensed under a Creative Commons Attribution-ShareAlike 4.0 International License (CC BY-SA 4.0).

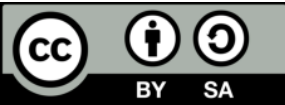

\section{INTRODUCTION}

Patient monitoring is an important part of the health care system both at the hospital and at home [1]. Patient monitoring can be done using pulse oximetry because it can detect the absorption of light varies based on the amount of oxygen in the blood [2]. Pulse oximetry is used to measure the per minute heart rate (BPM) and the percentage of oxygen saturation in the blood (SPO2) [3]. Changes in heart rate and oxygen saturation can affect the respiratory system if they show abnormal values. Respiratory disorders can cause asthma which is characterized by airway inflammation, airway obstruction, and the hyperresponsive airway can cause inflammation and swelling of the airways in the lungs [4]. In the past, asthma was commonly suffered by adults but now, asthma can also be suffered by children [5]. The direct cause of asthma is still unknown. However, various studies have shown that several factors can influence the increase in the number of asthma sufferers around the world, including genetic and environmental factors [6]. The number of asthmatics has increased significantly since the 1970s. In 2011, patients diagnosed with asthma were 235 million while 250,000 died due to asthma attacks. In 2014, the number of asthmatics increased to 334 million worldwide [7]. Asthma attacks are very difficult to predict because they often occur suddenly [8]. Most asthma deaths can be avoided by timely intervention or prevention [9]. In the management guidelines for asthma exacerbations (GINA), assume that heart rates from 100-120 bpm and $\mathrm{SpO} 2$ from $90-95 \%$ as mild or moderate asthma while heart rates are greater than $120 \mathrm{bpm}$ and $\mathrm{SpO} 2$ less than $90 \%$ as severe asthma [10]. Therefore it is needed a tool to detect asthma attacks making it easier for patient monitoring. In a previous study, in 2013 Nur Ilham Imarah made a study regarding the design of a monitoring tool to assess the severity of asthma in patients [11]. However, in that study, the device must be connected to a PC because the monitoring system uses the MATLAB application. Furthermore, in 2015 Kaushal et al 
made an asthma detection system using a pellet sensor by analyzing exhaled breath [12]. However, this tool has not been able to classify mild, moderate, and severe asthma conditions. Then, in 2015 Uwaoma et al made a tool to detect asthma symptoms using a smartphone in real-time [13]. However, in that study, there was no notification when an asthma attack occurred. Then, in 2016 Shaharum et al classified the severity of asthma using wheezing sound analysis in patients [14]. However, in this study, there were also no indicators when an asthma attack occurred. Furthermore, in 2016 Abinayaa et al made a portable monitoring tool for asthma patients [15]. However, these devices require Wi-Fi signals so that doctors can examine and diagnose the patient's condition from a distance. In the same year, Anumeha et al made detection and monitoring of asthma triggers using Zigbee [16]. However, in the detection device, there is no notification for a warning system of asthma triggers. Then, in 2017 Gouma et al made a tool for asthma monitoring by measuring the levels of nitric oxide in a patient's breath [17]. However, this study requires a PC for recording and processing data. Then, in 2018 Alexander et al made the design of a broadband microwave applicator to diagnose bronchial asthma [18]. However, this research requires high frequency through the chest and requires at least two different frequencies to diagnose. Furthermore, in 2018 Hong et al made the development of an electronic kit to detect asthma in human respiration [19]. However, this study requires a PC to see the graphical differences between normal people and people with asthma. In 2018 Siddiqui et al made a classification and analysis of the severity of chronic obstructive pulmonary disease and asthma using heart rate sensors and $\mathrm{SpO} 2[10][20]$. However, in that study there were no indicators and notifications about asthma classification.

Based on the identification of the problem above, the writer wants to make the Design of Asthma Detection Devices Through BPM and $\mathrm{SpO} 2$ Indicators. The making of this module is expected to make it easier for patients' families to find out the patient's location through SMS notifications if asthma patients who are outside the home experience an asthma attack suddenly so that it can be treated immediately. Because it is very difficult to predict acute asthma attacks because it often occurs suddenly and asthma can also cause death in patients due to breathing that can suddenly stop. For that reason, the writer wants to make a medium and severe asthma attack detection device that can be seen from the BPM and $\mathrm{SpO} 2$ values.

This Article is composed of: Chapter 1 introduction, Chapter 2 Material and Methods, Chapter 3 Result, Chapter 4 Discussion, Chapter 5 Conclusion, and Chapter 6 Reference.

\section{MATERIALS AND METHODS}

\section{A. Experimental Setup}

This study used on normal subject aged 22 years old and weighing $66 \mathrm{~kg}$. Subjects were taken randomly by conducting 3 trials and each trial was taken 6 data.

\section{B. Materials and Device}

This study uses the finger sensor (Nellcor, DS-100A, Mexico) to measure oxygen saturation in the blood ( $\mathrm{SpO} 2)$ and heart rate (BPM). A microcontroller (Arduino Nano, R3, Italy) was used to process the data. LCD (Oled, 0,96", China) as a display for displaying the value $\mathrm{SpO} 2$ and BPM. Using the 3 batteries as a power supply (Toshiba, Li-ion, China). Pulse Oximetry (Elitech, Fox-1, Indonesia) was used as a means of comparison. GSM module (SIM800L, China) was used to send message notifications. GPS module (Ublox, Neo M8N, China) was used to determine patient location.

\section{Experiment}

In this study, researchers measured the value of oxygen saturation $(\mathrm{SpO} 2)$ and heart rate $(\mathrm{BPM})$ from the respondent who was randomly selected and the results were compared with standard.

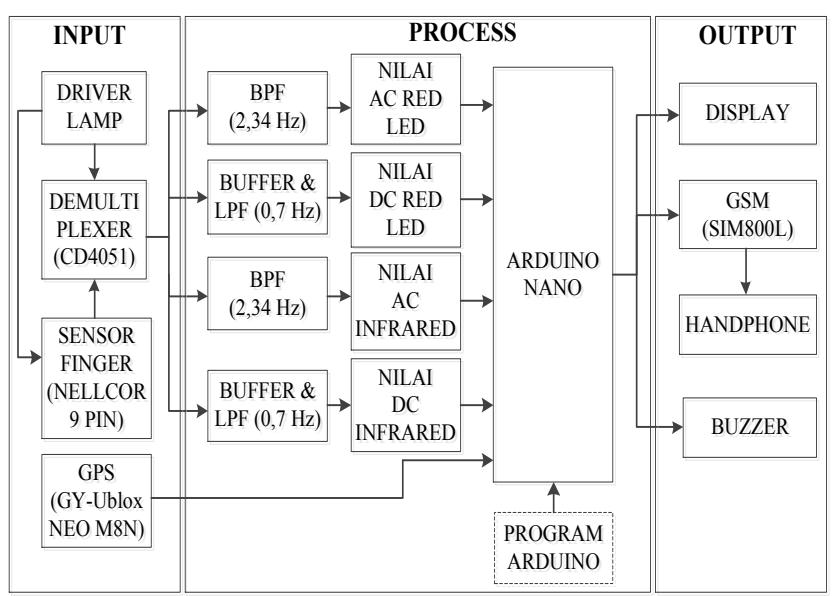

Fig. 1. The Diagram Block Design of Asthma Detection Devices Through Heart Rate and Oxygen Saturation Indicators

\section{The Diagram Block}

In (Fig. 1.), the finger sensor gets the voltage supply from the lamp driver. Inside the lamp driver there is a range of astable, transistor drivers and IC logic circuit NOT 7404, transistor drivers connected to red led and infrared will be set on using an astable circuit which is a frequency generator of $1,000 \mathrm{~Hz}$, while IC logic NOT functions to condition different logic between red led and infrared so as not to light simultaneously. Then the finger sensor will produce an output in the form of photodiode output from the transmitter red led and infrared. From the finger sensor and lamp, the driver will enter the demultiplexer circuit, where when the demultiplexer gets logic 1 from IC logic NOT 7404 will enter the BPF circuit to produce AC Red led values and to the buffer \& LPF circuit to produce DC Red led values. When the demultiplexer gets logic 0 from IC the logic NOT 7404 will enter the BPF circuit to produce AC Infrared values and to the buffer \& LPF circuit to produce DC Infrared values. The four outputs of the $\mathrm{SpO} 2$ circuit will enter the microcontroller via Arduino Nano so that 
the $\mathrm{SpO} 2$ and BPM values will be displayed on the display. When the SPO2 and BPM values are not normal (moderate asthma or severe asthma value categories), the buzzer will sound and the device will send a notification in the form of an SMS containing a link to the location of an asthmatic patient to his family.

\section{E. The Flowchart}

In (Fig. 2.), when the device is turned on or start, the microcontroller will initialize the ADC input in the form of AC Red led, AC Infrared, DC Red led, and DC Infrared data. Of the 4 ADC inputs, the SpO2 signal will be detected, from the $\mathrm{SpO} 2$ signal the $\mathrm{BPM}$ value will be obtained. The $\mathrm{SpO} 2$ and $\mathrm{BPM}$ values will be used to detect conditions by monitoring the SPO2 and BPM values through the index finger in patients who have been diagnosed with asthma. When the SPO2 and BPM values are still in the normal category, the SPO2 and BPM values will only be monitored on the display. However, when the SPO2 and BPM values are not normal (in the category of moderate asthma values that is, in the presence of features such as heart rate from 100-120 bpm and $\mathrm{SpO} 2$ from $90-95 \%$ and severe asthma value categories ie, in the presence of features such as a heart rate greater than $120 \mathrm{bpm}$ and an SPO2 of less than 90\%), the buzzer will sound and the device will send a notification in the form of an SMS containing a link to the location of an asthmatic patient to his family.

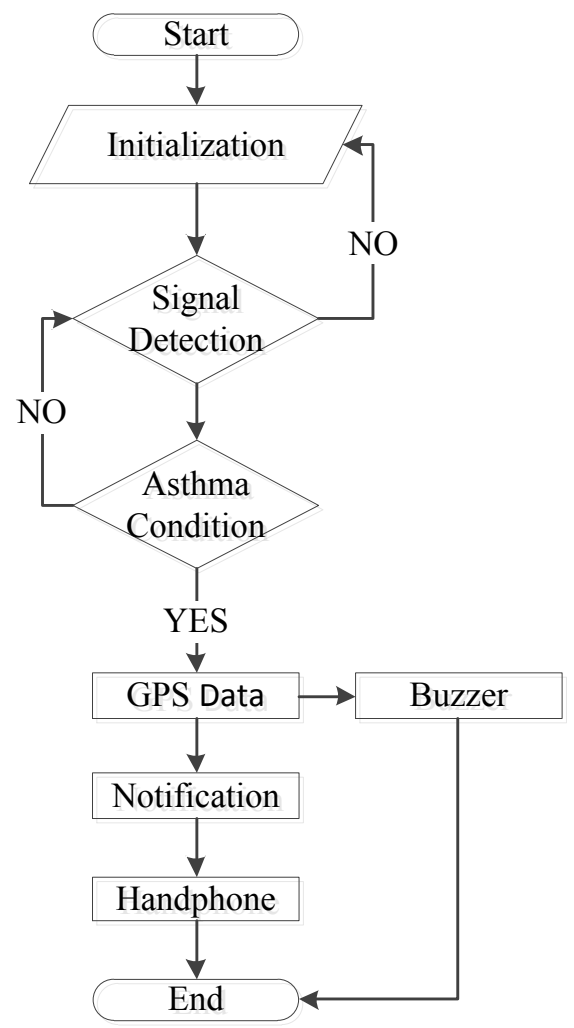

Fig. 2. The Flowchart Design of Asthma Detection Devices Through Heart Rate and Oxygen Saturation Indicators

\section{F. Circuit}

\section{1) Astable}

In (Fig. 3.), the astable circuit is a frequency generator of $1.000 \mathrm{~Hz}$ which is used to adjust the red led and infrared flares of the transistor driver.

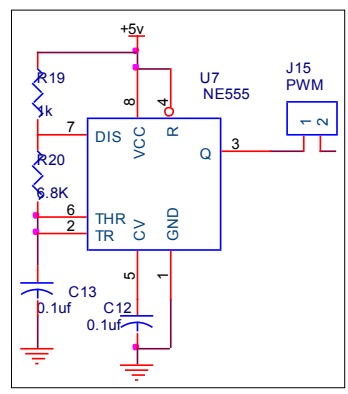

Fig. 3. Astable Circuit Uses NE555 for $1000 \mathrm{~Hz}$ Frequency Generator

\section{2) Driver Transistor}

In (Fig. 4.) driver transistors are used to condition the different logic (1/0) between the red led and infrared so they do not light up simultaneously.

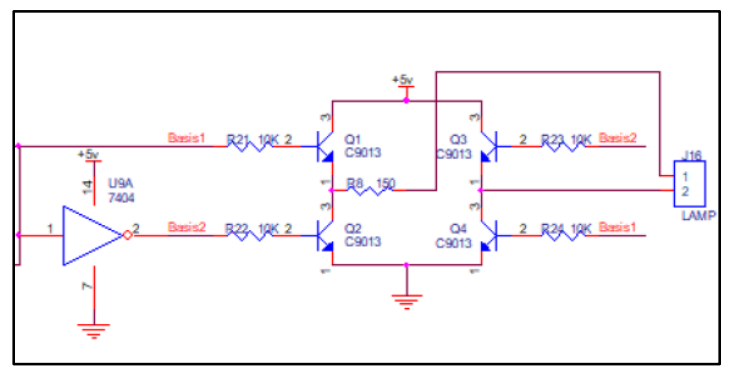

Fig. 4. Circuit of Driver Transistor Uses C9013 to Condition The Different Logic $(1 / 0)$

\section{3) Amplifier and Filter}

In (Fig. 5.) amplifiers and filters are used to give a better emphasis on the noise signal after the first filter is done.

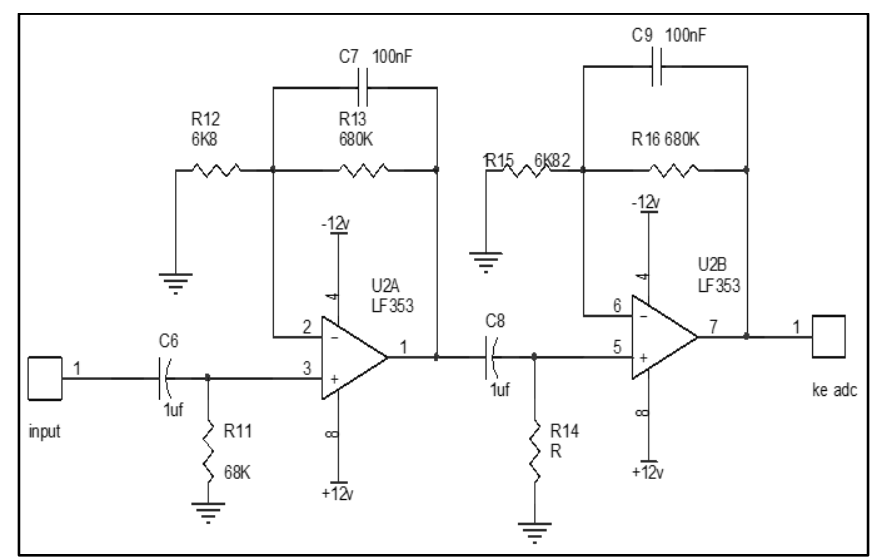

Fig. 5. Circuit of Amplifier and Filter Uses LF353 to Emphasis Noise Signals 


\section{4) Low Pass Filter 0,7 Hz}

In (Fig. 6), low pass filter circuit with a cut off frequency of $0.7 \mathrm{~Hz}$ to discard the AC signal and pass the DC signal. Where the amplitude will be suppressed when the input frequency exceeds the cut-off frequency.

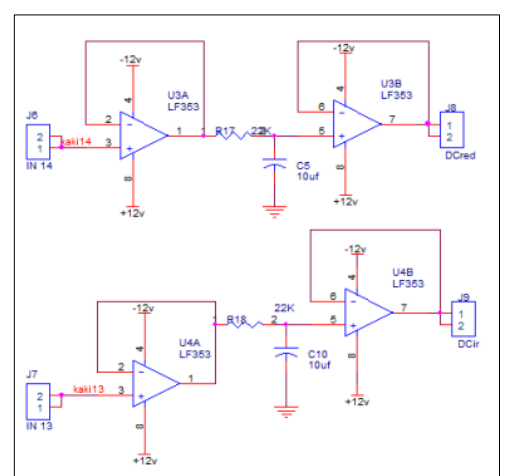

Fig. 6. Circuit of Low Pass Filter $0,7 \mathrm{~Hz}$ Uses Capacitor and Resistor to Suppress The Amplitude When The Input Frequency Exceeds 0,7 Hz

\section{5) High Pass Filter 2,34 Hz}

In (Fig. 7), a high-pass filter circuit is used to pass the amplitude when the input frequency exceeds the cut-off frequency.

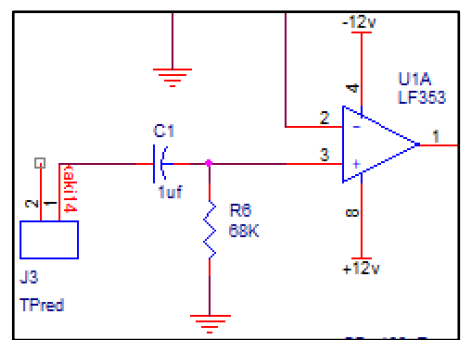

Fig. 7. Circuit of High Pass Filter 2,34 Hz Uses Capacitor and Resistor to Pass The Amplitude When The Input Frequency Exceeds $2.34 \mathrm{~Hz}$

\section{RESULTS}

\section{A. Results of Respondent}

In (Fig. 8), researchers measured the value of oxygen saturation $(\mathrm{SpO} 2)$ and heart rate $(\mathrm{BPM})$ from the respondent who was randomly selected and the results were compared with standard.

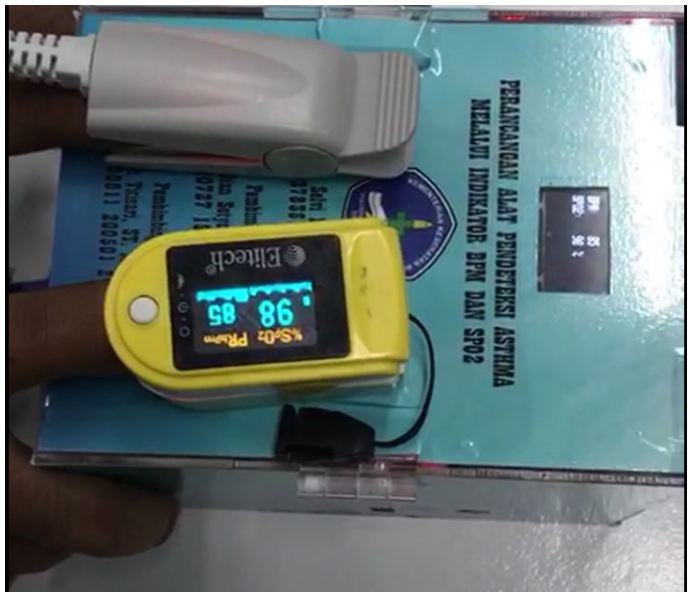

Fig. 8. Results of Respondent to Be Compared With Standard (Pulse Oximetry Elitech)

\section{B. Listing program for $\mathrm{SpO} 2$}

In the initial process of compiling the program, the program will initialize the input data from the $\mathrm{SpO} 2$ circuit consisting of ACred, ACir, DCred, and DCir. These four data will be entered into the ADC module when switching to digital data. Then from the $4 \mathrm{ADC}$ inputs, the $\mathrm{SpO} 2$ signal will be detected, from this $\mathrm{SpO} 2$ signal the percentage value of $\mathrm{SpO} 2$ will be used to support the patient's requirements.

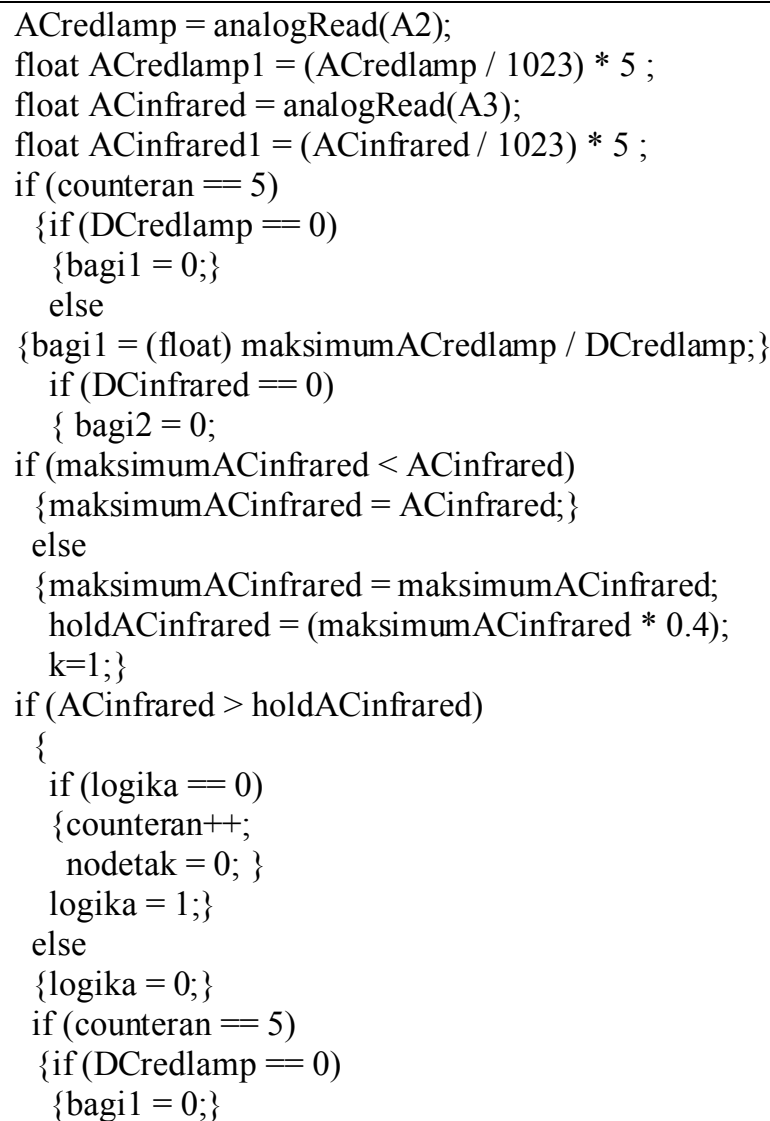




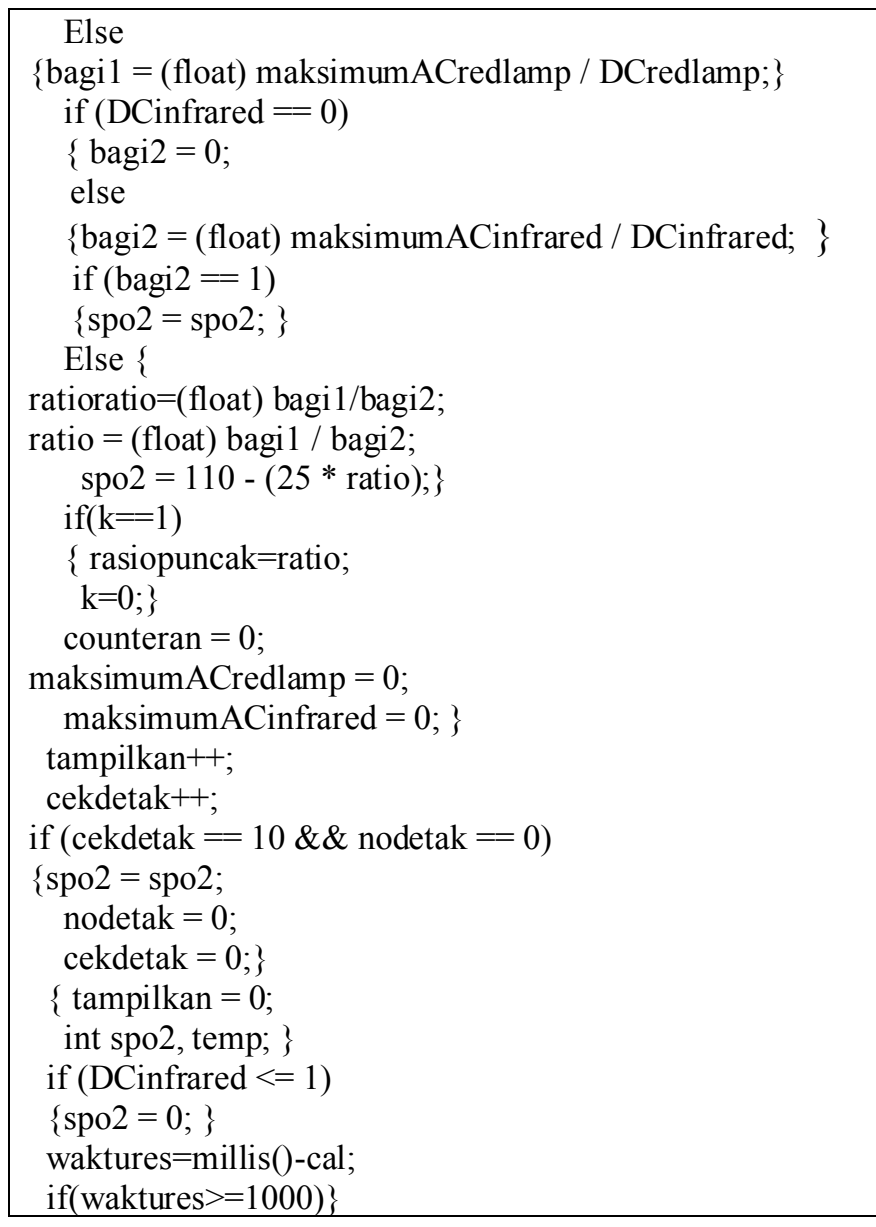

\section{Listing Program for BPM}

The BPM value is taken from the peak to peak signal graph on $\mathrm{SpO} 2$ where the BPM program will calculate the number of peak to peak values on the $\mathrm{SpO} 2$ graph in minutes. So that the heart rate associated with activity in the heart can be measured by the number of contractions as beats per minute (bpm). The graph on the $\mathrm{SpO} 2$ is very influential on the BPM value because if the oxygen saturation value $(\mathrm{SpO} 2)$ is low then it can cause the heart to pump faster so that the heart rate per minute (BPM) becomes high.

void bpm ()\{
sensor $=$ ACredlamp;
if $($ ref $<=$ sensor $)\{$ ref=-sensor; $\}$
else $\{$ ref $=$ ref; hold $=($ ref* 0.6$) ;\}$
waktuu=millis () -waktureset;
if $($ sensor $>$ hold $)$
$\{$ beat $=1 ;\}$
waktumonostabil=waktumonostabil $+100 ;$
if $($ beat $==1)\{$
if $($ sensor $<($ hold $* 0.85))$
$\{$ detak $++;$
beat $=0 ;$

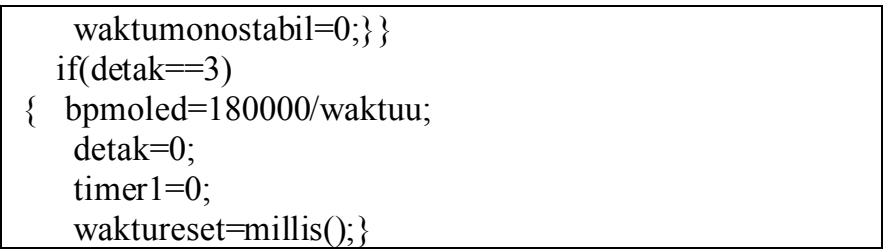

\section{Listing Program for Massage}

SIM800L GSM Module is a GSM module that can function as an SMS gateway when connected to a microcontroller. So that the GSM module can be used optimally, it must be filled with a sim card that has a good signal so that it can send or receive SMS quickly. This module is used to send SMS to families to find out when a sudden asthma attack occurs in asthmatics who are outside the home. The SMS is in the form of an asthma sufferer's location link that will be directly connected to Maps.

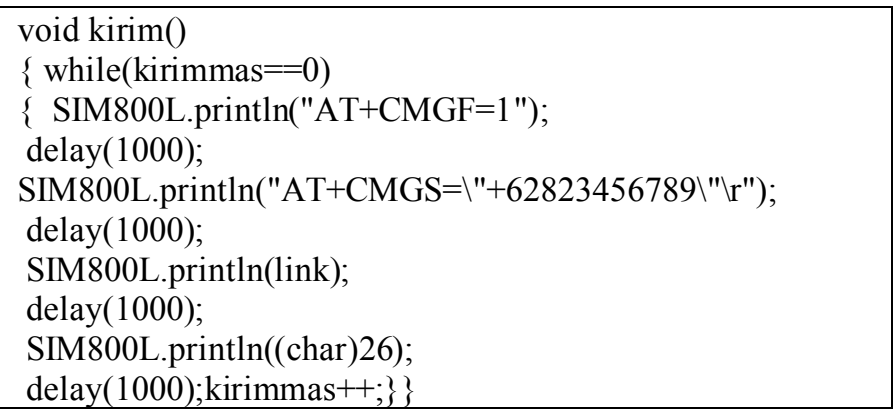

\section{E. Listing Program for Location}

The Ublox NEO M8N GPS module is very easy to use and is connected to a microcontroller or can be accessed directly with a PC. This GPS module supports knowing the position (coordinates) with the help of GPS satellites. This module is used to determine the location of the victim as a compass that occurs with the help of satellites and latitude with the help of GPS satellites

\begin{tabular}{|l|}
\hline void GPS ()\{ \\
if(Serial.available( $)$ ) \\
\{gps.encode(Serial.read ()$) ;\}$ \\
if(gps.location.isUpdated ()$)$ \\
\{ latitude = gps.location.lat ()$;$ \\
longitude = gps.location.lng( $) ;$ \\
Serial.println(link); \\
lo =longitude; \\
la =latitude; \\
link = "www.google.com/maps/place/" + String(la, 6) + "," \\
+ String(lo, 6$) ;\}$
\end{tabular}




\section{F. BPM Measurement Result for Respondent}

In (TABLE I.), the result of a comparison between the module and the comparison tool by conducting three trials and each experiment is taken 6 measurement data, then the average results and standard deviation of the BPM will be obtained. The largest value of the average BPM is 88.33 and the smallest value is 84.67 . The largest value of the standard deviation of BPM is 3.141 and the smallest value is 0.754 . The largest BPM error value is $3.548 \%$ and the smallest is $2.472 \%$.

TABLE I. BPM MEASUREMENT RESULT FOR RESPONDENT

\begin{tabular}{cccc}
\hline Measurement & Mean & SD & (\%) Error \\
\hline 1 & 85.50 & 2.757 & 2.495 \\
\hline 2 & 88.33 & 1.967 & 3.548 \\
\hline 3 & 84.67 & 3.141 & 2.472 \\
\hline
\end{tabular}

G. SpO2 Measurement Result for Respondent

In (TABLE II.), the results of the comparison between the module and the comparison tool by conducting three trials and each experiment is taken 6 measurement data, then the average results and standard deviation of the $\mathrm{SpO} 2$ value will be obtained. The largest value of the average $\mathrm{SpO} 2$ is 99 and the smallest value is 97.33 , while the largest value of the standard deviation of $\mathrm{SpO} 2$ is 0.517 and the smallest value is 0 . The highest $\mathrm{SpO} 2$ error value obtained is $1.715 \%$ and the smallest value is $0.168 \%$.

TABLE II. SPO2 MEASUREMENT RESUlt FOR RESPONDENT

\begin{tabular}{cccc}
\hline Measurement & Mean & SD & (\%) Error \\
\hline 1 & 98.00 & 0.000 & 0.168 \\
\hline 2 & 99.00 & 0.000 & 1.715 \\
\hline 3 & 98.33 & 0.517 & 0.34 \\
\hline
\end{tabular}

\section{H. Display of Massage and Location}

When the device identifies an abnormality in a patient's condition (asthma) using the $\mathrm{SpO} 2$ and BPM indications, the device will send an SMS notification containing a link that when opened will be directly connected to maps because it contains longitude and latitude points with the help of GPS satellites. This can be seen in (Fig. 9. \& Fig. 10.).

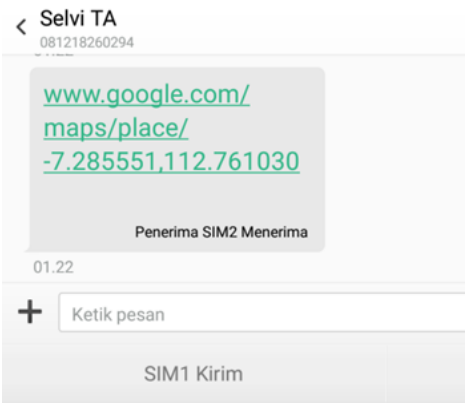

Fig. 9. Display Notification Message from the Device in the form of a Link

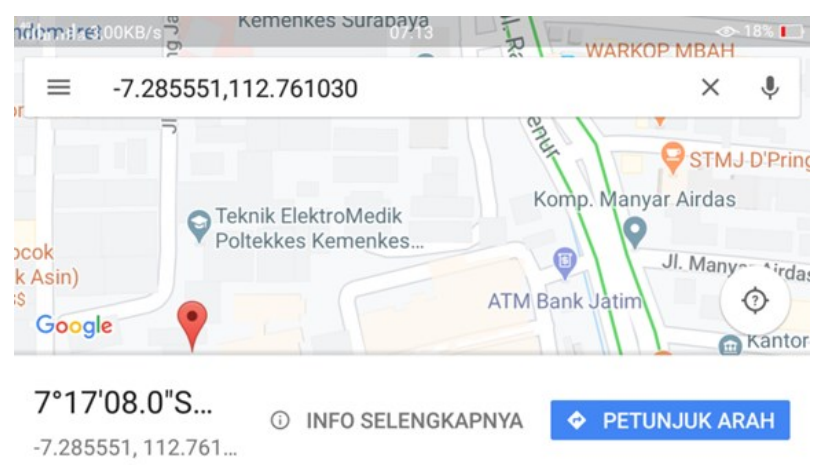

Fig. 10. Display When a Link is Opened Using Maps

\section{DISCUSSION}

In (TABLE I. \& TABLE. II), shows the measurement of the BPM and $\mathrm{SpO} 2$ values of respondents where these values can be used to classify the patient's condition as normal, mild asthma, and severe asthma. It has also been investigated by Siddiqui et al in 2018 to make Severity Classification of Chronic Obstructive Pulmonary Disease and Asthma with Heart Rate and SpO2 Sensors [10]. However, in that study, there were no indicators and notifications about asthma classification. But the difference between this study and that research is that in addition to detecting asthma, the device also comes with a notification message in the form of a patient's location that will be sent to his family in the event of an asthma attack so that it can be treated immediately. This can be seen in (Fig. 9. \& Fig. 10.).

\section{CONCLUSION}

The purpose of this study is to make an asthma detection tool through $\mathrm{BPM}$ and $\mathrm{SpO} 2$ indicators for patients who have been diagnosed with asthma equipped with notifications, making it easier for families to know when a sudden asthma attack occurs in asthmatics who are outside the home. The testing of this tool is done by comparing the module with a standard measuring instrument that produces the highest value of oxygen saturation error which is $1.715 \%$ and the largest value of heart rate error is $3.548 \%$. The results showed that the device was appropriate to use, because in the Medical Devices Test and Calibration Guidelines of the Ministry of Health of the Republic of Indonesia in 2001, the maximum limit in oxygen saturation error tolerance was $2 \%$, and heart rate was 
$5 \%$. The results of this study can be implemented in patients who have been diagnosed with asthma so that it can facilitate the family in monitoring the patient's condition. Further development in this study can be done by improving the astable and filter circuit so that the error value is smaller so that the error rate in heart rate and oxygen saturation in the device, when compared with the comparison, is also smaller.

\section{REFERENCES}

[1] A. Rahman, T. Rahman, N. H. Ghani, S. Hossain, and J. Uddin, "IoT Based patient monitoring system using ECG sensor," 1st Int. Conf. Robot. Electr. Signal Process. Tech. ICREST 2019, pp. 378-382, 2019.

[2] N. Gazivoda, Ž. Beljić, P. Sovilj, D. Pejić, and B. Vujičić, "Measurement firmware for pulse oximetry sensor," 2016 Zooming Innov. Consum. Electron. Int. Conf. ZINC 2016, pp. 42-45, 2016.

[3] P. M. Mohan, V. Nagarajan, and A. A. Nisha, "A frame work to estimate heart rate and arterial oxygen saturation (Spo2)," Proc. 2017 IEEE Int. Conf. Commun. Signal Process. ICCSP 2017, vol. 2018-Janua, pp. 1645-1648, 2018.

[4] G. S. Walia and R. K. Sharma, "Level of asthma: Mathematical formulation based on acoustic parameters," Conf. Adv. Signal Process. CASP 2016, pp. 24-27, 2016.

[5] S. Shikalgar, S. Marathe, P. Rai, and D. Nadar, "Rule extraction for detection and prevention of asthma attacks," Proc. 2015 IEEE 3rd Int. Conf. MOOCs, Innov. Technol. Educ. MITE 2015, pp. 437-440, 2016.

[6] A. Kassem, M. Hamad, and C. El Moucary, "A smart spirometry device for asthma diagnosis," Proc. Annu. Int. Conf. IEEE Eng. Med. Biol. Soc. EMBS, vol. 2015-Novem, pp. 1629-1632, 2015.

[7] M. Liu and M. C. Huang, "Asthma Pattern Identification via Continuous Diaphragm Motion Monitoring," IEEE Trans. Multi-Scale Comput. Syst., vol. 1, no. 2, pp. 76-84, 2015.

[8] Q. T. Do, A. K. Doig, T. C. Son, and J. M. Chaudri, "Personalized Prediction of Asthma Severity and Asthma Attack for a Personalized Treatment Regimen," Proc. Annu. Int. Conf. IEEE Eng. Med. Biol. Soc. EMBS, vol. 2018-July, pp. 1-5, 2018.

[9] F. Yang et al., "Identify asthma genes across three phases based on protein-protein interaction network," IET Syst. Biol., vol. 9, no. 4, pp. 135-140, 2015.

[10] T. Siddiqui and B. I. Morshed, "Severity Classification of Chronic Obstructive Pulmonary Disease and Asthma with Heart Rate and $\mathrm{SpO} 2$ Sensors *," IEEE Int. Conf. Electro Inf. Technol., no. 1637250, pp. 2929-2932, 2018.

[11] N. Ii. B. M. Yusop and M. B. Malarvili, "Design of asthmatic severity monitoring tool," Ijareeie, vol. 2, no. 12, pp. 5800-5809, 2013.

[12] P. Kaushal and R. P. Mudhalwadkar, "Pellet sensor based asthma detection system using exhaled breath analysis," 2015 Int. Conf. Ind. Instrum. Control. ICIC 2015, no. Icic, pp. 139-142, 2015.

[13] C. Uwaoma and G. Mansingh, "Towards real-time monitoring and detectime monitoring of asthma symptoms on resource-constraint mobile device," 2015 12th Annu. IEEE Consum. Commun. Netw. Conf. CCNC 2015, pp. 47-52, 2015.

[14] S. M. Shaharum, S. Aniza, K. Sundaraj, R. Palaniappan, and K. Helmy, "Classification of asthma severity levels by wheeze sound analysis," Proc. - 2016 IEEE Conf. Syst. Process Control. ICSPC 2016, no. December, pp. 172-176, 2017.

[15] B. Abinayaa and A. A. Raja, "Smart Portable Monitoring Device for Asthma Patients," Middle-East J. Sci. Res., vol. 24, no. S1, pp. 136-142, 2016.

[16] M. A. Lal, M. Girish, and A. Kulkarni, "Detection and Monitoring of Asthma Trigger Factor using Zigbee," Int. Adv. Res. J. Sci. Eng. Technol. ISO, vol. 3297, no. 7, pp. 134-137, 2007.

[17] P. Gouma, M. Stanacevic, Y. Karimi, J. Huang, and G. Jodhani, "No nanosensor and single exhale breathalyzer for asthma monitoring,"
ISOEN 2017 - ISOCS/IEEE Int. Symp. Olfaction Electron. Nose, Proc., vol. 2017-May, pp. 1-3, 2017.

[18] A. V. Dem'Yanenko, I. V. Semernik, and Y. V. Nevstruev, "Designing of broadband microwave applicator for the bronchial asthma diagnosis device," Proc. 2018 IEEE Conf. Russ. Young Res. Electr. Electron. Eng. ElConRus 2018, vol. 2018-Janua, pp. 1199-1202, 2018.

[19] C. S. Hong, A. S. A. Ghani, and I. M. Khairuddin, "Development of an Electronic Kit for detecting asthma in Human Respiratory System," IOP Conf. Ser. Mater. Sci. Eng., vol. 319, no. 1, 2018.

[20] T. Siddiqui and B. I. Morshed, "Severity Exploratory Model Analysis of Chronic Obstructive Pulmonary Disease and Asthma with Heart Rate and SpO2," IEEE Int. Conf. Electro Inf. Technol., pp. 913-916, 2018. 